\title{
Efficacy and Safety Analysis of Oxaliplatin-based Chemotherapy for Advanced Gastric Cancer
}

\author{
KYOKO INADOMI ${ }^{1}$, HITOSHI KUSABA ${ }^{1}$, YUZO MATSUSHITA ${ }^{2}$, RISA TANAKA ${ }^{2}$, KENJI MITSUGI ${ }^{2}$, \\ KOHEI ARIMIZU ${ }^{3}$, GEN HIRANO ${ }^{3}$, AKITAKA MAKIYAMA ${ }^{3}$, HIROFUMI OHMURA ${ }^{4}$, KEITA UCHINO ${ }^{4}$, \\ FUMIYASU HANAMURA ${ }^{5}$, YOSHIHIRO SHIBATA ${ }^{5}$, MIYUKI KUWAYAMA ${ }^{6}$, TAITO ESAKI ${ }^{6}$, \\ KOTOE TAKAYOSHI ${ }^{1}$, SHUJI ARITA ${ }^{7}$, HIROSHI ARIYAMA ${ }^{1}$, KOICHI AKASHI $^{1}$ and EISHI BABA ${ }^{7}$ \\ ${ }^{1}$ Department of Medicine and Biosystemic Science, \\ Kyushu University Graduate School of Medical Sciences, Fukuoka, Japan; \\ ${ }^{2}$ Department of Medical Oncology, Hamanomachi Hospital, Fukuoka, Japan; \\ ${ }^{3}$ Department of Hematology and Oncology, \\ Japan Community Healthcare Organization Kyushu Hospital, Kitakyushu, Japan; \\ ${ }^{4}$ Department of Medical Oncology, Clinical Research Institute, \\ National Hospital Organization Kyushu Medical Center, Fukuoka, Japan; \\ ${ }^{5}$ Department of Medical Oncology, Fukuoka Wajiro Hospital, Fukuoka, Japan; \\ ${ }^{6}$ Department of Gastrointestinal and Medical Oncology, \\ National Kyushu Cancer Center, Fukuoka, Japan; \\ ${ }^{7}$ Department of Comprehensive Clinical Oncology, Faculty of Medical Sciences, \\ Kyushu University, Fukuoka, Japan
}

\begin{abstract}
Background: Significant efficacy of oxaliplatinbased chemotherapy has been demonstrated for advanced gastric cancer (AGC). However, the appropriate dose of oxaliplatin, and the efficacy and toxicity of administration of oxaliplatin subsequent to cisplatin therapy still remain unclear. Patients and Methods: In total, 55 patients with AGC that were scheduled to receive oxaliplatin-based chemotherapy were prospectively examined. Results: The median age was 67 years and oxaliplatin was administered to 39 (71\%) patients as first-line and in 16 (29\%) patients as second-line therapy. An initial dose of 130 or $100 \mathrm{mg} / \mathrm{m}^{2}$ of oxaliplatin was administered to 11 and 36 patients, respectively. The overall response rates $(O R R)$ and median progression free survival (mPFS) were 86 and 33\%, and 7.2 and 7.8 months, respectively. Compared to $100 \mathrm{mg} / \mathrm{m}^{2}$, the relative dose intensity was significantly lower and severe toxicity tended to
\end{abstract}

This article is freely accessible online.

Correspondence to: Eishi Baba, MD, Ph.D., Department of Comprehensive Clinical Oncology, Faculty of Medical Sciences, Kyushu University, 3-1-1 Maidashi, Higashiku, Fukuoka 812-8582, Japan. Tel: +81 926426921, Fax +81926426922, e-mail: e-baba@concology.med.kyushu-u.ac.jp

Key Words: Gastric cancer, oxaliplatin, cisplatin, chemotherapy. increase with oxaliplatin at $130 \mathrm{mg} / \mathrm{m}^{2}$. A total of 10 patients (18\%) had a prior cisplatin-based therapy. The ORR of the patients pretreated with cisplatin was $14 \%$ and the mPFS was 6.1 months. Conclusion: An initial oxaliplatin dose of 130 $\mathrm{mg} / \mathrm{m}^{2}$ resulted in a good response, but tended to increase the risk of toxicity. Subsequent oxaliplatin-based therapy after cisplatin exhibited modest efficacy, especially in cases with cisplatin intolerance.

Gastric cancer (GC) is the fourth most frequent malignant tumor and the second most common cause of tumor death in the world (1). Recurrent GC after curative resection and initially unresectable metastatic GC (advanced GC; AGC) are treated with systemic chemotherapy (CT), that can prolong survival and maintain quality of life. For the initial CT, combination consisting of fluorouracil or fluoropyrimidine and platinum has been demonstrated to be effective. The triplet regimen including fluoropyrimidine, platinum and epirubicin is often used in European countries (2). Effectiveness of a triplet of docetaxel, cisplatin and fluorouracil has been shown in the United States (3). The standard therapy for patients with AGC in Japan has been a combination of the oral fluoropyrimidine S-1 and cisplatin (SP) based on the results of the phase 3 SPIRITS study (4). Another fluoropyrimidine, capecitabine, has also been shown to be effective for AGC in combination with cisplatin (5).

Oxaliplatin has also been employed for systemic CT for AGC in combination with fluorouracil or fluoropyrimidine 
$(2,5,6)$. Non-inferiority of oxaliplatin over cisplatin in terms of overall survival (OS) was demonstrated in the randomized phase III REAL-2 study, in which the dosage of oxaliplatin was $130 \mathrm{mg} / \mathrm{m}^{2}$ (2). A phase II study that examined a combination CT of S-1 plus oxaliplatin (SOX) exhibited efficacy for AGC (7). Subsequently, a phase III G-SOX study aimed at confirming the effectiveness of SOX for Japanese patients with AGC demonstrated similar progression-free survival (PFS) and OS by using a dose of oxaliplatin of 100 $\mathrm{mg} / \mathrm{m}^{2}$. This lower dose of oxaliplatin was used because of frequent thrombocytopenia induced by oxaliplatin in the previous phase II study $(7,8)$. Therefore, different doses of oxaliplatin have been used in individual regimens in Japanese clinical practice; however, it remains to be clarified which of these doses are the most effective and the safest.

Both cisplatin and oxaliplatin are forms of platinum and can inhibit DNA-duplication by cross-linking double-stranded DNA. Cross-resistance between the two drugs is thought to be unlikely because of the different repair mechanisms for the DNA damage induced by each drug (9-15). Several clinical studies have been conducted to address the efficacy of oxaliplatin-based CT against cisplatin-resistant cancer (1618). A phase I study that examined a combination of fluorouracil, leucovorin, mitomycin $\mathrm{C}$ and oxaliplatin for cisplatin-resistant AGC demonstrated a response rate (RR) of $35 \%$, PFS of 4.1 months and OS of 8 months (17). A phase II study that employed FOLFOX4 (fluorouracil, leucovorin and oxaliplatin) showed an RR of $26 \%$ and a median OS of 7.3 months (18). Although these studies suggested efficacy of oxaliplatin-based CT against cisplatin-resistant AGC, sequential usage of cisplatin- and oxaliplatin-based CTs has not been well determined, especially in prospective studies.

The use of oxaliplatin for AGC was approved in Japan in 2015. Some patients with cisplatin-resistant AGC have been treated with oxaliplatin-based CT, and patients intolerant to cisplatin have continued their platinum-based CT by switching from cisplatin to oxaliplatin in clinical practice in Japan. However, the efficacy and safety of administration of oxaliplatin subsequent to cisplatin therapy are poorly understood. In addition, clinical studies of pre-operative SP therapy were recently conducted $(19,20)$. Conservation of the efficacy and safety of oxaliplatin-based CT in patients who were treated with perioperative cisplatin-based CT in cases of recurrence is an important issue. This study prospectively examined the efficacy and safety of oxaliplatin-based CT in Japanese clinical practice, especially in terms of differences in doses of oxaliplatin and the subsequent use of oxaliplatin after cisplatin therapy.

\section{Patients and Methods}

Patients. Patients who started treatment between October 2014 and February 2016 at any of six institutions participating in the Kyushu
Medical Oncology Group with written informed consent were assessed. The eligibility criteria were: 20 years or older, histologically proven metastatic or recurrent gastric adenocarcinoma or esophagogastric junction adenocarcinoma, patients who were planned to receive oxaliplatin-based chemotherapy at any treatment line. This study was approved by the Ethics Committee of Kyushu University Hospital (Approval No. 27-80) and was performed according to the guidelines for biomedical research specified in the Declaration of Helsinki.

Treatment. All patients were treated with systemic CT consisting of a combination of SOX, oxaliplatin plus capecitabine (CapeOX), SOX plus trastuzumab, or oxaliplatin, S-1 plus leucovorin. In the SOX regimen, 40-60 mg of S-1 was orally administered twice-daily on days $1-14$, depending on the patient's body surface area, and $100 \mathrm{mg} / \mathrm{m}^{2}$ or $130 \mathrm{mg} / \mathrm{m}^{2}$ oxaliplatin was administered intravenously on day 1 every 3 weeks. In the CapeOX regimen, $1,000 \mathrm{mg} / \mathrm{m}^{2}$ capecitabine was orally administered twice-daily on days $1-14$ and $100 \mathrm{mg} / \mathrm{m}^{2}$ or 130 $\mathrm{mg} / \mathrm{m}^{2}$ oxaliplatin was administered intravenously on day 1 every 3 weeks. Trastuzumab was administered at a dose of $8 \mathrm{mg} / \mathrm{kg}$ for the initial course and at a dose of $6 \mathrm{mg} / \mathrm{kg}$ from the second course on day 1 every 3 weeks. In the combination regimen of oxaliplatin, S- 1 plus leucovorin, $85 \mathrm{mg} / \mathrm{m}^{2}$ of oxaliplatin was administered on day 1 every 2 weeks, and $60 \mathrm{mg} \mathrm{S}-1$ and $25 \mathrm{mg}$ leucovorin were administered twice daily on days 1-7 every 2 weeks. These treatments were continued until disease progression, unacceptable toxicity or the decision to discontinue by the patient or the investigator. Dose reduction and treatment delay were performed basically following the dose modification and interruption protocol of the G-SOX study (8).

Assessments. Assessment of tumor lesions was basically performed by computed tomographic scan. Gastrointestinal endoscopy, magnetic resonance imaging and positron-emission tomography were also utilized for examination of lesions if necessary. Tumor responses were assessed according to the Response Evaluation Criteria in Solid Tumors (RECIST) version 1.1 (21). PFS was defined as the period from the initiation of oxaliplatin-based CT to the day of tumor progression or the day of death from any cause. Additionally, for patients who had first-line cisplatin therapy and were then administered oxaliplatin-based therapy as a second line, the period from the initiation of cisplatin therapy to the termination of oxaliplatin-based CT was also examined, which was defined as whole-platinum PFS. All adverse events (AEs) were evaluated according to the National Cancer Institute Common Terminology Criteria for Adverse Events (CTCAE) version 4.0 (22). The most severe grades of $\mathrm{AE}$ in the period of chemotherapy were recorded.

Statistics. PFS was estimated using the Kaplan-Meier method. Comparison of tumor responses and the survival of patient groups according to the dose of oxaliplatin was performed using Fisher's exact test and the log-rank test, respectively. Comparison of baseline characteristics before the initiation of oxaliplatin-based CT was performed using Student's $t$-test. Values of $p<0.05$ were considered statistically significant. All statistical analyses were carried out using JMP software (SAS Institute Japan, Tokyo, Japan).

\section{Results}

Patient characteristics. In total, 60 patients with AGC who were treated with oxaliplatin-based CT were registered, of 
Table I. Patient characteristics $(n=55)$.

\begin{tabular}{|c|c|c|}
\hline Characteristic & No. & $\%$ \\
\hline Median age (range), years & $67(31-83)$ & - \\
\hline \multicolumn{3}{|l|}{ Gender } \\
\hline Male & 35 & 64 \\
\hline Female & 20 & 36 \\
\hline \multicolumn{3}{|l|}{ PS } \\
\hline 0 & 29 & 53 \\
\hline 1 & 24 & 44 \\
\hline 2 & 1 & 2 \\
\hline 3 & 1 & 2 \\
\hline \multicolumn{3}{|l|}{ Disease status } \\
\hline Advanced & 48 & 87 \\
\hline Recurrent & 7 & 13 \\
\hline \multicolumn{3}{|l|}{ Histology } \\
\hline Well/moderately differentiated adenocarcinoma & 26 & 47 \\
\hline $\begin{array}{l}\text { Poorly differentiated adenocarcinoma/ } \\
\text { signet-ring cell carcinoma }\end{array}$ & 28 & 51 \\
\hline Mucinous adenocarcinoma & 1 & 2 \\
\hline \multicolumn{3}{|l|}{ HER2 status } \\
\hline Positive & 3 & 5 \\
\hline Negative & 47 & 85 \\
\hline Not measured & 5 & 10 \\
\hline \multicolumn{3}{|l|}{ Site of metastasis } \\
\hline Lymph node & 31 & 56 \\
\hline Peritoneum & 28 & 51 \\
\hline Liver & 15 & 27 \\
\hline Lung & 4 & 7 \\
\hline Bone & 3 & 5 \\
\hline \multicolumn{3}{|l|}{ No. of organs with metastases } \\
\hline 0 & 1 & 2 \\
\hline 1 & 32 & 58 \\
\hline 2 or more & 22 & 40 \\
\hline \multicolumn{3}{|l|}{ Previous therapy for cancer } \\
\hline Surgery & 16 & 29 \\
\hline Adjuvant CT & 8 & 15 \\
\hline \multicolumn{3}{|l|}{ No. of prior CT regimens } \\
\hline 0 & 39 & 71 \\
\hline 1 & 16 & 29 \\
\hline Drug administered in prior $\mathrm{CT}$ & $\mathrm{n}=16$ & \\
\hline Cisplatin & 10 & 63 \\
\hline$S-1$ & 16 & 100 \\
\hline Capecitabine & 0 & 0 \\
\hline Trastuzumab & 2 & 13 \\
\hline \multicolumn{3}{|l|}{ Number of cycles of prior } \\
\hline \multicolumn{3}{|l|}{ Reasons for cisplatin discontinuation } \\
\hline Adverse event & 8 & 80 \\
\hline Progressive disease & 2 & 20 \\
\hline
\end{tabular}

PS: Eastern Cooperative Oncology Group performance status, CT: chemotherapy, HER2: human epidermal growth factor receptor 2.

whom 55 who were treated with oxaliplatin-based CT as firstor second-line therapy were analyzed (Table I). Severe comorbidities prior to $\mathrm{CT}$ were observed in 18 patients $(33 \%)$, including renal dysfunction (creatinine clearance $<50 \mathrm{ml} / \mathrm{min}$ ) in $10(18 \%)$, pulmonary disease in two $(4 \%)$, poorly
Table II. Details of the oxaliplatin-based chemotherapy (CT) as firstline and second-line $(n=55)$.

\begin{tabular}{lcc}
\hline & No. & $\%$ \\
\hline Regimen & 50 & \\
$\quad$ S-1 plus oxaliplatin & 3 & 51 \\
$\quad$ Capecitabine plus oxaliplatin & 2 & 4 \\
$\quad$ Trastuzumab, S-1 and oxaliplatin & 11 & 20 \\
Initial dose of oxaliplatin & 36 & 65 \\
$130 \mathrm{mg} / \mathrm{m}^{2}$ & 8 & 15 \\
$100 \mathrm{mg} / \mathrm{m}^{2}$ & & \\
$<100 \mathrm{mg} / \mathrm{m}^{2}$ & 21 & 38 \\
Initial dose reduction of S-1 or capecitabine & Median & Range \\
$\quad$ Yes & 7 & $1-22$ \\
& 5 & $1-17$ \\
& 69 & $17-100$ \\
\hline Number of cycles of oxaliplatin-based CT & 79 & $27-100$ \\
Number of cycles of oxaliplatin & & \\
RDI of oxaliplatin $\%$ ) & & \\
RDI of capecitabine/S-1 (\%) &
\end{tabular}

RDI: Relative dose intensity.

controlled diabetes mellitus (hemoglobin-A1c level $>7.0 \%$ ) in two (4\%) and moderate to severe ascites in three (5\%). At the initiation of oxaliplatin-based CT, poorly controlled hypertension, and hepatic and bone marrow dysfunctions of CTC-AE grade 3 or more were noted in one patient (2\%).

Treatments and their efficacy for the whole patient group. An oxaliplatin-based CT regimen was performed in the 55 patients (Table II). Most patients (65\%) were treated with an initial dose of oxaliplatin of $100 \mathrm{mg} / \mathrm{m}^{2}$. One patient received $85 \mathrm{mg} / \mathrm{m}^{2}$ of oxaliplatin every 2 weeks and this was considered as the equivalent of a dose of $130 \mathrm{mg} / \mathrm{m}^{2}$ every 3 weeks. In the 55 patients, the median number of cycles and the median relative dose intensity (RDI) of oxaliplatin-based CT were shown in Table II.

Reasons for discontinuation of oxaliplatin-based CT included progressive disease in 32 patients $(58 \%)$, AEs in three $(5 \%)$, patient's wish in two (4\%), complete response (CR) in one (2\%), complete resection in one (2\%), and one patient lost due to transfer to another hospital (2\%). Fifteen patients (27\%) continued to receive oxaliplatin-based CT.

The best response of the oxaliplatin-based $\mathrm{CT}$ is shown in Table III. The ORR was $46 \%$ and the disease control rate (DCR; $\mathrm{CR}$, partial response (PR), stable disease (SD) and non-CR/nonprogressive disease (PD)) was $85 \%$ (Table III). The median follow-up period was 13.1 months. The median PFS was 7.8 months (95\% confidence interval $(\mathrm{CI})=6.1-10.2$ months) (Figure 1A). For patients who received oxaliplatin-based $C T$ as first-line therapy, the ORR was $60 \%$ and DCR was $92 \%$; the median PFS was 9.8 months (95\% CI=7.2-12.3 months) (Figure 1B). 
Table III. Best objective response of patients with first-line and second line ( $n=55)$ and subgroup analyses.

\begin{tabular}{|c|c|c|c|c|c|}
\hline & All patients & Oxaliplatin $130 \mathrm{mg} / \mathrm{m}^{2}$ & Oxaliplatin $100 \mathrm{mg} / \mathrm{m}^{2}$ & $p$-Value & Cisplatin-pretreated \\
\hline Number of patients & 55 & 11 & 36 & - & 10 \\
\hline \multicolumn{6}{|l|}{ Efficacy } \\
\hline $\mathrm{CR}$ & 3 & 0 & 3 & - & 1 \\
\hline PR & 14 & 6 & 5 & - & 0 \\
\hline SD & 12 & 1 & 10 & - & 4 \\
\hline PD & 5 & 0 & 3 & - & 1 \\
\hline NE & 3 & 0 & 3 & - & 1 \\
\hline Non-CR and non-PD & 18 & 4 & 12 & - & 3 \\
\hline ORR & $46 \%$ & $86 \%$ & $33 \%$ & 0.028 & $14 \%$ \\
\hline DCR & $85 \%$ & $91 \%$ & $87 \%$ & 0.231 & $80 \%$ \\
\hline
\end{tabular}

CR: Complete response, PR: partial response, SD: stable disease, PD: progressive disease, NE: not evaluable, ORR: overall response rate. DCR: disease control rate, PFS: progression free survival.

Comparison of characteristics and efficacy of CT according to the dose of oxaliplatin. Tumor response in terms of the initial dose of oxaliplatin of the 55 patients treated with firstline and second-line therapy was examined (Table III). The median age of the patients treated with an oxaliplatin dose of $130 \mathrm{mg} / \mathrm{m}^{2}$ and $100 \mathrm{mg} / \mathrm{m}^{2}$ as the first-line and second-line was 63 and 67 years, respectively. Pathohistological diagnosis, distribution of organs with metastasis, number of organs with metastasis, and severe comorbidities including poor PS and organ disorders were similar in both groups.

The number of patients who received oxaliplatin-based CT as second-line therapy was one $(9 \%)$ at a dose of $130 \mathrm{mg} / \mathrm{m}^{2}$ and $10(28 \%)$ at $100 \mathrm{mg} / \mathrm{m}^{2}$. Of patients who received the $130 \mathrm{mg} / \mathrm{m}^{2}$ dose of oxaliplatin, nine $(82 \%)$ were treated with the SOX regimen and two (18\%) with CapeOX. All 36 patients who received the $100 \mathrm{mg} / \mathrm{m}^{2}$ dose were treated with the SOX regimen. The median number of cycles of oxaliplatin-based CT at a dose of $130 \mathrm{mg} / \mathrm{m}^{2}$ and $100 \mathrm{mg} / \mathrm{m}^{2}$ was 8 and 7, respectively, and the median number of cycles of oxaliplatin was 5 for both doses. The median RDI of oxaliplatin was significantly lower at a dose of $130 \mathrm{mg} / \mathrm{m}^{2}$ than at a dose of $100 \mathrm{mg} / \mathrm{m}^{2}(48 \%$, range $=22-78 \%$ and $74 \%$, range $=17-100 \%$ ), respectively; $p=0.0024)$. The median RDI of fluoropyrimidine was similar in both groups, being $80 \%$ (range $=34-100$ ) at a dose of $130 \mathrm{mg} / \mathrm{m}^{2}$ and $80 \%$ (range $=27-$ 100) at $100 \mathrm{mg} / \mathrm{m}^{2}$. The ORR of patients treated with oxaliplatin was more favorable at a dose of $130 \mathrm{mg} / \mathrm{m}^{2}$ than $100 \mathrm{mg} / \mathrm{m}^{2}$ at $86 \%$ and $33 \%$, respectively $(p=0.028)$ (Table III). The median PFS of the patients treated with oxaliplatin at a dose of $130 \mathrm{mg} / \mathrm{m}^{2}$ and $100 \mathrm{mg} / \mathrm{m}^{2}$ was 7.2 and 7.8 months, respectively $(95 \% \mathrm{CI}=5.1$ months-not reached and 5.6-10.2 months, respectively; $p=0.6417$ ) (Figure 1C).

Characteristics of oxaliplatin-based CT treatment and efficacy for patients who had prior cisplatin therapy. Ten patients who had received cisplatin prior to oxaliplatin-based CT for AGC (cisplatin-pretreated patients) were further analyzed. Their median age was 65 years (range $=50-75$ years). Pathohistological diagnosis, distribution of organs with metastasis and number of organs with metastasis were similar to those of the total patient group. All 10 patients had received S-1 plus cisplatin regimen as first-line therapy, and no patient had CT containing trastuzumab. The baseline characteristics of cisplatin-pretreated patients were compared to those of patients who were not administered cisplatin before the initiation of oxaliplatin-based CT (cisplatin-untreated patients). Renal dysfunction (creatinine clearance $<50 \mathrm{ml} / \mathrm{min}$ ) was significantly increased in the cisplatin-pretreated patients (five patients, 50\%) compared to the cisplatin-untreated patients (five patients, 11\%) $(p=0.0117)$. The initial dose of oxaliplatin was $130 \mathrm{mg} / \mathrm{m}^{2}$ in one patient $(10 \%), 100 \mathrm{mg} / \mathrm{m}^{2}$ in eight $(80 \%)$ and less than $100 \mathrm{mg} / \mathrm{m}^{2}$ in one $(10 \%)$. Nine patients $(90 \%)$ were treated with the SOX regimen, and one $(10 \%)$ with CapeOX. The median number of cycles of oxaliplatin-based CT was 7 (range=1-17) and that of oxaliplatin was 6 (range $=1-17$ ). The median RDI of oxaliplatin was $69 \%$ (range $=17-100 \%$ ). Reasons for discontinuation of oxaliplatin-based CT were progressive disease in six patients $(60 \%)$ and AEs in one patient $(10 \%)$; this therapy continued in three patients $(30 \%)$. The ORR of the patients was $14 \%$, and the DCR was $80 \%$. The median PFS of oxaliplatin-based CT was 6.1 months (95\% CI=0.9 months-not reached) (Figure 1D).

Additionally, we assessed the therapeutic impact of sequential CT of cisplatin and oxaliplatin. We defined the period from the initiation of S-1 plus cisplatin therapy to the termination of oxaliplatin-based $\mathrm{CT}$ as the second-line therapy as whole-platinum PFS. The median whole-platinum PFS in 10 patients was 10.9 months (95\% CI=5.1-69.3 months) (Figure 1E).

Safety. Various non-hematological and hematological toxicities were observed in the patients (Table IV). Oxaliplatin-specific peripheral neuropathy appeared in 45 patients $(75 \%)$. Severe 
A

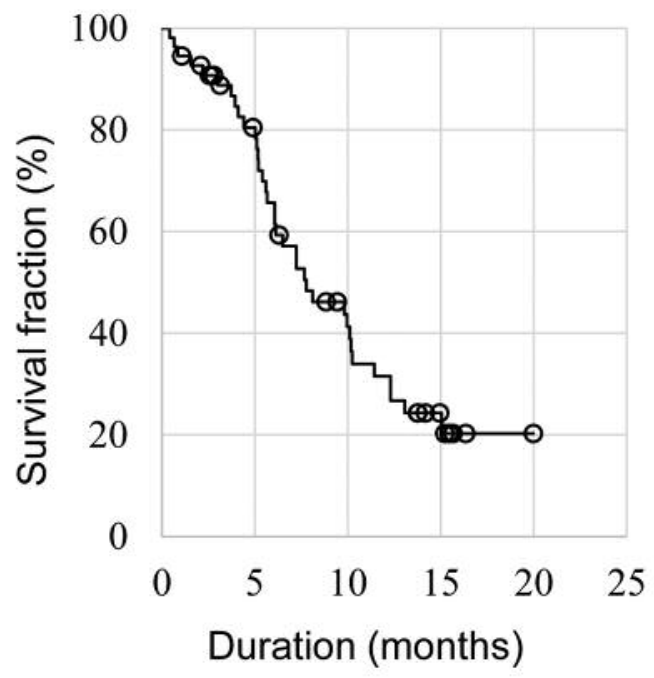

B

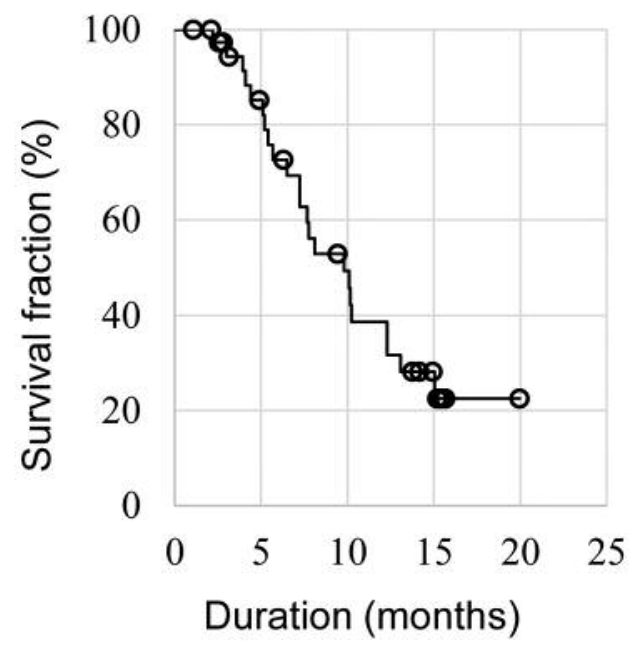

Figure 1. Kaplan-Meier curves of progression-free survival (PFS) according to patient group: A: Treatment with first-line and second-line oxaliplatin-based therapy $(n=55) ; B$ : treatment with first-line oxaliplatin-based therapy $(n=39) ; C$; PFS of patients treated with the different initial doses of oxaliplatin; $D$ : treatment with second-line oxaliplatin-based therapy of cisplatin-pretreated patients $(n=10) ; E$ : whole-platinum PFS of cisplatin-pretreated patients $(n=10)$.
C

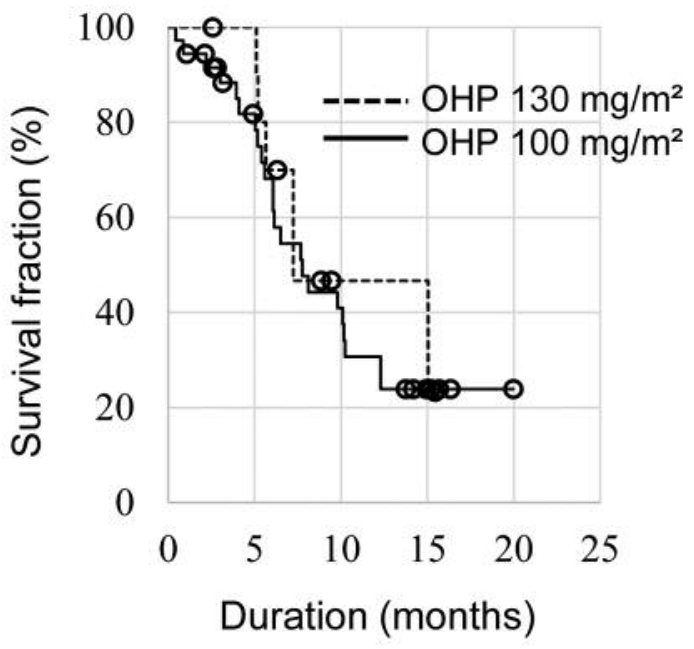

D

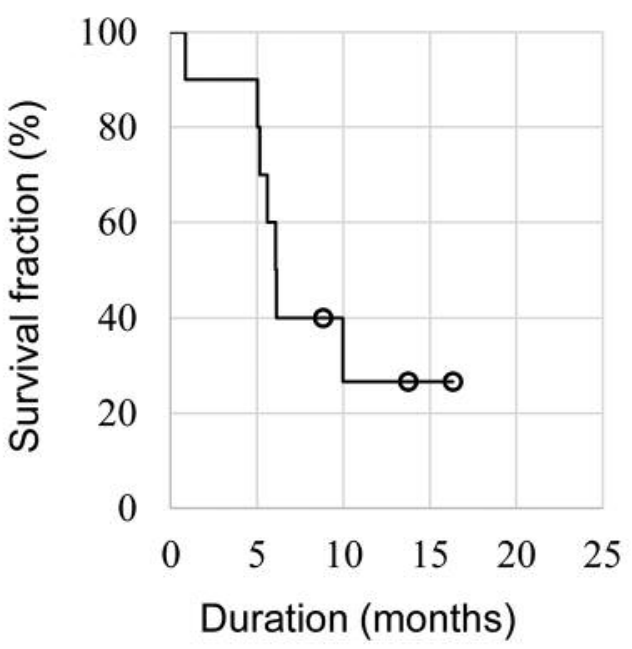

E

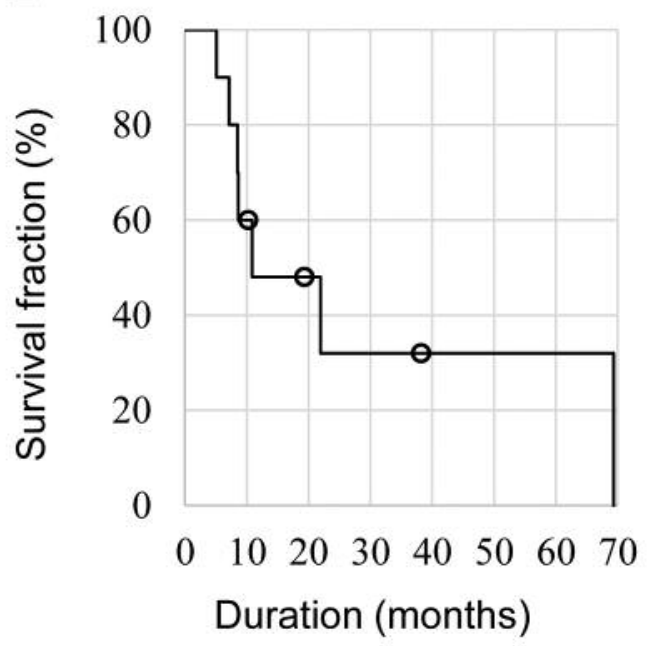


Table IV. Adverse events of patients with first-line and second line $(n=55)$ and subgroup analyses.

\begin{tabular}{|c|c|c|c|c|c|c|c|c|}
\hline \multirow[t]{2}{*}{ Adverse event } & \multicolumn{2}{|c|}{$\begin{array}{c}\text { All patients, } \\
\mathrm{n}(\%) \\
\mathrm{n}=55\end{array}$} & \multicolumn{2}{|c|}{$\begin{array}{c}\text { Oxaliplatin } \\
130 \mathrm{mg} / \mathrm{m}^{2}, \mathrm{n}(\%) \\
\mathrm{n}=11\end{array}$} & \multicolumn{2}{|c|}{$\begin{array}{c}\text { Oxaliplatin } \\
100 \mathrm{mg} / \mathrm{m}^{2}, \mathrm{n}(\%) \\
\mathrm{n}=36\end{array}$} & \multicolumn{2}{|c|}{$\begin{array}{l}\text { Cisplatin-pretreated, } \\
\text { n }(\%) \\
n=10\end{array}$} \\
\hline & All grade & Grade $3 / 4$ & All grade & Grade $3 / 4$ & All grade & Grade $3 / 4$ & All grade & Grade $3 / 4$ \\
\hline Severe non-hematological & - & $19(35)$ & - & $4(36)$ & - & $7(19)$ & - & $1(10)$ \\
\hline Nausea & $33(55)$ & $3(5)$ & $6(55)$ & $1(9)$ & $20(56)$ & $1(3)$ & $7(70)$ & 0 \\
\hline Vomiting & $10(17)$ & 0 & $2(18)$ & 0 & $6(17)$ & 0 & $2(20)$ & 0 \\
\hline Anorexia & $49(82)$ & $6(10)$ & $8(73)$ & $1(9)$ & $29(81)$ & $2(6)$ & $10(100)$ & 0 \\
\hline Abdominal pain & $7(12)$ & $1(2)$ & 0 & 0 & $6(17)$ & $1(3)$ & 0 & 0 \\
\hline Fatigue & $34(57)$ & 0 & $9(82)$ & 0 & $17(47)$ & 0 & $6(60)$ & 0 \\
\hline Diarrhea & $21(35)$ & 0 & $4(36)$ & 0 & $11(31)$ & 0 & $5(50)$ & 0 \\
\hline Peripheral neuropathy & $45(75)$ & $1(2)$ & $8(73)$ & $1(9)$ & $28(78)$ & 0 & $8(80)$ & 0 \\
\hline Hand-Foot syndrome & $3(5)$ & 0 & $1(9)$ & 0 & $1(3)$ & 0 & 0 & 0 \\
\hline Thromboembolism & $2(4)$ & $1(2)$ & $1(9)$ & $1(9)$ & $1(3)$ & 0 & $1(10)$ & 0 \\
\hline Febrile neutropenia & 0 & 0 & 0 & 0 & 0 & 0 & 0 & 0 \\
\hline Albumin decrease & $57(95)$ & 0 & $11(100)$ & 0 & $33(92)$ & 0 & $9(90)$ & 0 \\
\hline Total bilirubin increase & $15(25)$ & $1(2)$ & $4(36)$ & 0 & $9(25)$ & 0 & $1(10)$ & 0 \\
\hline AST increase & $51(84)$ & $4(7)$ & $11(100)$ & 0 & $29(81)$ & $2(6)$ & $9(90)$ & 0 \\
\hline ALT increase & $23(37)$ & 0 & $6(55)$ & 0 & $13(36)$ & 0 & $4(40)$ & 0 \\
\hline ALP & $37(62)$ & $1(2)$ & $8(73)$ & 0 & $21(58)$ & 0 & $7(70)$ & 0 \\
\hline Cr ratio increase* & $17(28)$ & $1(2)$ & $2(18)$ & 0 & $10(28)$ & 0 & $3(30)$ & $1(10)$ \\
\hline Severe hematological & - & $14(25)$ & - & $4(36)$ & - & $6(17)$ & - & $2(20)$ \\
\hline Leukopenia & $23(38)$ & $4(7)$ & $7(64)$ & $1(9)$ & $11(31)$ & $2(6)$ & $5(50)$ & $1(10)$ \\
\hline Neutropenia & $39(65)$ & $8(13)$ & $11(100)$ & $2(18)$ & $24(67)$ & $4(11)$ & $5(50)$ & $1(10)$ \\
\hline Lymphocytopenia & $25(42)$ & $3(5)$ & $6(55)$ & 0 & $11(31)$ & $1(3)$ & $4(40)$ & 0 \\
\hline Anemia & $54(90)$ & $6(10)$ & $11(100)$ & $1(9)$ & $34(94)$ & $2(6)$ & $9(90)$ & $2(20)$ \\
\hline Thrombocytopenia & $44(73)$ & $2(4)$ & $9(82)$ & $1(9)$ & $23(64)$ & $1(3)$ & $8(80)$ & 0 \\
\hline
\end{tabular}

AST: Aspartate aminotransferase, ALT: alanine aminotransferase, ALP: alkaline phosphatase, Cr: creatinine.*From baseline.

non-hematological toxicity of grade 3 or 4 was observed in 19 patients $(35 \%)$, and severe hematological toxicity was observed in 14 patients $(25 \%)$. When the groups treated with the different doses of oxaliplatin were compared, severe nonhematological and hematological toxicity of grade 3 or 4 was observed more frequently in patients treated with an oxaliplatin dose of $130 \mathrm{mg} / \mathrm{m}^{2}$ than in those treated with $100 \mathrm{mg} / \mathrm{m}^{2}$ (four patients $(36 \%)$ and seven patients $(19 \%), p=0.2126$, four patients $(36 \%)$ and six patients $(17 \%), p=0.2555$, respectively). In the cisplatin-pretreated group, severe toxicity was anemia in two patients $(20 \%)$. The frequency of severe thrombocytopenia, peripheral neuropathy, and creatinine baseline ratio increase was not increased, but the frequency of severe anemia was tended to increase in this group compared to patients who had no prior chemotherapy of cisplatin (two patients (20\%) and one patient (2\%), $p=0.0818)$.

\section{Discussion}

The present study was conducted to examine the efficacy and safety of oxaliplatin-based CT for AGC in Japanese clinical practice. Since the efficacy of platinum for AGC has been demonstrated in first-line therapy in pivotal clinical studies, oxaliplatin-based CT was performed in the first-line therapy of 39 patients. Of these patients, S-1 plus oxaliplatin was the most frequently used combination. A previous phase III clinical study that compared S-1 plus cisplatin with SOX (GSOX study) reported that the median PFS, ORR and DCR of the SOX arm were 5.5 months, $55.7 \%$ and $85.2 \%$, respectively (8). The REAL-2 study showed that the PFS and ORR of the combination therapy with epirubicin, oxaliplatin and capecitabine were 7.0 months and $47.9 \%$, respectively (2). In the present study, the ORR of first-line oxaliplatinbased CT was $60 \%$ and the median PFS was 9.6 months (95\% CI=7.2-12.3 months), which compared favorably with the results of the above pivotal studies. Possible reasons for alteration of the efficacy of oxaliplatin-based CT in the present study might be differences in patient background such as age and comorbidities, disease status including the number of metastatic organs, the pathway of metastasis and histological features. Subgroup analysis of the G-SOX study showed that favorable efficacy of SOX therapy was observed in the patient group with peritoneal dissemination, which consisted of $19 \%$ of enrolled patients with AGC (8). Fifty- 
one percent of patients in the present study harbored peritoneal dissemination, which might be one reason for the modest efficacy. In terms of AEs, grade 3 or 4 anemia, neutropenia, thrombocytopenia and anorexia were reported in $15.1,19.5,10.1$ and $15.4 \%$ of patients, respectively, in the G-SOX study (8). Consistent with the safety profile of the G-SOX study, the oxaliplatin-based CT employed in the present study was safely administered for the most part, although severe anemia in cisplatin-pretreated patients should be carefully monitored.

When the two different initial doses of oxaliplatin were compared, the RDI of oxaliplatin was significantly lower and more severe AEs occurred in patients treated with a dose of $130 \mathrm{mg} / \mathrm{m}^{2}$ than in those treated with $100 \mathrm{mg} / \mathrm{m}^{2}$. Based on large-scale clinical trials of the combination of SOX, including the G-SOX study, an initial dose of oxaliplatin 100 $\mathrm{mg} / \mathrm{m}^{2}$ has been adopted in Japan. In the present study, the RDI of oxaliplatin at a dose of $130 \mathrm{mg} / \mathrm{m}^{2}$ was $48 \%$, which was low compared to the median RDI of $100 \mathrm{mg} / \mathrm{m}^{2}$ in the G-SOX study, which was $79.0 \%$. In addition, all of the patients in the present study that were treated with $130 \mathrm{mg} / \mathrm{m}^{2}$ underwent dose reduction or oxaliplatin withdrawal due to AEs. Although the ORR was better in the patients treated with $130 \mathrm{mg} / \mathrm{m}^{2}$ compared to those treated with $100 \mathrm{mg} / \mathrm{m}^{2}$, and to the results of the G-SOX study, PFS was equivalent, suggesting the possibility that an initial dose of $130 \mathrm{mg} / \mathrm{m}^{2}$ oxaliplatin is effective in cases where tumor shrinkage is anticipated. However, since no data regarding the effects of a dose of $130 \mathrm{mg} / \mathrm{m}^{2}$ are available in the literature, a prospective study comparing oxaliplatin doses of $130 \mathrm{mg} / \mathrm{m}^{2}$ and $100 \mathrm{mg} / \mathrm{m}^{2}$ for AGC is desired.

Both oxaliplatin and cisplatin are categorized as forms of platinum that exhibit an inhibitory effect on DNA duplication by forming cross-links in DNA strands. Because the mechanisms by which the DNA damage induced by the cross-linking of oxaliplatin and cisplatin are repaired are different, cross-resistance to the two drugs is thought to be low (9-15). Cisplatin tends to induce tumor cell toxicity by forming intra-strand cross-links. The DNA repair machinery of the tumor cell is believed to ignore the DNA deformation caused by the cross-linking of cisplatin, which links neighboring guanine bases. On the other hand, because the DNA deformation induced by oxaliplatin cross-linking is extensive, the DNA repair enzyme hMutS-alpha cannot access the binding site of the oxaliplatin-DNA strand in order to repair it (9-15). The low possibility of cross-resistance between cisplatin and oxaliplatin suggests that sequential administration of these agents might have favorable efficacy. However, in the treatment of AGC in clinical practice, there are few chances to administer these agents sequentially because a platinum-double regimen is often employed in the initial therapy, and monotherapy or a combination of paclitaxel and ramucirumab are performed in the subsequent therapy (23). Several evaluations of the efficacy of oxaliplatin for cisplatin-resistant AGC have been reported. Al-Batran SE et al. reported a phase I study of a combination therapy of fluorouracil, leucovorin, oxaliplatin and mitomycin C (FLOM) for cisplatin-resistant AGC. In total, 20 AGC patients were treated with FLOM therapy; the ORR was $35 \%$, the median PFS was 4.1 months and the OS was 8 months (17). A phase 2 study using a combination of fluorouracil, leucovorin and oxaliplatin (FOLFOX4) for cisplatin-resistant AGC demonstrated a RR of $26 \%$ and a median OS of 7.3 months. These reports suggested favorable efficacy of oxaliplatin against cisplatin-resistant AGC; however, no prospective study was performed to determine these sequential CTs.

It may be possible that both platinum agents could be administered to AGC patients in the perioperative CT and recurrent disease. S-1 monotherapy for one year or a combination of capecitabine plus oxaliplatin for 6 months have been standard adjuvant CT for AGC patients who had curative surgery in Japan $(24,25)$. Since clinical studies assessing adjuvant platinum-based CT have not shown effectiveness in a study of SP plus radiation or in the ARTIST study, they may not be employed in the adjuvant setting. On the other hand, for neoadjuvant chemotherapy, a phase 2 clinical study to assess the effect of a pre-operative CT with S-1, docetaxel and cisplatin is now underway against AGC with extensive lymph node metastasis (JCOG1002) (20). A randomized phase III trial of surgery plus neoadjuvant S-1 plus cisplatin compared with surgery alone for type 4 and large type 3 gastric cancer (JCOG 0501) is also ongoing (19). In cases in which the efficacy of neoadjuvant CTs employing cisplatin are proven, there may be an opportunity to administer oxaliplatin to recurrence cases after the CT and surgery (26-28).

Second-line chemotherapy has been proven to contribute to survival in AGC (29). Clinical studies of such CT compared with best supportive care showed an mPFS of 3.0-4.0 months in the CT group. In a phase 3 randomized study that compared weekly paclitaxel versus irinotecan for AGC patients after FU plus platinum therapy, the mPFS was 3.6 versus 2.3 months, respectively (30). A combination of ramucirumab plus weekly paclitaxel demonstrated an mPFS of 4.4 months (23). In the present study, the mPFS of oxaliplatin-based CT was 6.1 months and the median whole-platinum PFS was 10.9 months in the cisplatin-pretreated patients, which suggests a relatively favorable survival benefit compared with previous reports. It is interesting that the cisplatin-pretreated group exhibited better survival with subsequent oxaliplatin-based CT than when considered as part of the whole-platinum survival group. No significant difference was seen between the PFS of the first-line oxaliplatin group and that of the wholeplatinum cisplatin-pretreated patients. Taking these results 
into consideration, the present observation could suggest a survival benefit of oxaliplatin-based CT even after cisplatin-based CT. Although a prospective study that would examine the effect of sequential CT of cisplatinoxaliplatin for AGC is desired in order to clarify its actual impact on survival, the present findings might be of importance in the present situation.

The present study demonstrated that oxaliplatin-based CT administration to Japanese AGC patients harboring a variety of backgrounds could be effective and safe, especially for patients with a prior treatment with cisplatin-based CT. These findings suggest the possibility of selecting oxaliplatin-based CT for cases of especially cisplatin intolerant patients and patients after cisplatin-containing regimens in neo-adjuvant CT and surgery. An initial oxaliplatin dose of $130 \mathrm{mg} / \mathrm{m}^{2}$ could be effective in cases where tumor shrinkage is anticipated but tended to increase the risk of toxicity.

\section{Conflicts of Interest}

Eishi Baba and Koichi Akashi are conducting research sponsored by Yakult Honsha Co., Ltd. The other Authors declare that they have no conflict of interest.

\section{Acknowledgements}

The Authors thank the medical staff of each institution who contributed to treatment of the patients.

\section{References}

1 Ferlay J, Bray F, Parkin DM and Pisani P (eds.): Globocan 2000: Cancer Incidence and Mortality Worldwide (IARC Cancer Base No. 5). Lyon: IARC Press; 2001.

2 Cunningham D, Starling N, Rao S, Iveson T, Nicolson M, Coxon F, Middleton G, Daniel F, Oates J and Norman AR: Capecitabine and oxaliplatin for advanced esophagogastric cancer. N Engl J Med 358: 36-46, 2008.

3 Van Cutsem E, Moiseyenko VM, Tjulandin S, Majlis A, Constenla M, Boni C, Rodrigues A, Fodor M, Chao Y, Voznyi E, Risse ML and Ajani JA: Phase III study of docetaxel and cisplatin plus fluorouracil compared with cisplatin and fluorouracil as first line therapy for advanced gastric cancer: a report of the V325 study group. J Clin Oncol 24: 4991-4997, 2006.

4 Koizumi W, Narahara H, Hara T, Takagane A, Akiya T, Takagi M, Miyashita K, Nishizaki T, Kobayashi O, Takiyama W, Toh Y, Nagaie T, Takagi S, Yamamura Y, Yanaoka K, Orita H and Takeuchi M: S-1 plus cisplatin versus S-1 alone for first-line treatment of advanced gastric cancer (SPIRITS trial): a phase III trial. Lancet Oncol 9: 215-221, 2008.

5 Kang YK, Kang WK, Shin DB, Chen J, Xiong J, Wang J, Lichinitser M, Guan Z, Khasanov R, Zheng L, Philco-Salas M, Suarez T, Santamaria J, Forster $G$ and McCloud PI: Capecitabine/cisplatin versus 5 -fluorouracil/cisplatin as first-line therapy in patients with advanced gastric cancer: a randomised phase III noninferiority trial. Ann Oncol 20: 666-673, 2009.
6 Al-Batran SE, Hartmann JT, Probst S, Schmalenberg H, Hollerbach S, Hofheinz R, Rethwisch V, Seipelt G, Homann N, Wilhelm G, Schuch G, Stoehlmacher J, Derigs HG, HegewischBecker S, Grossmann J, Pauligk C, Atmaca A, Bokemeyer C, Knuth A and Jäger E: Phase III trial in metastatic gastroesophageal adenocarcinoma with fluorouracil, leucovorin plus either oxaliplatin or cisplatin: a study of the Arbeitsgemeinschaft Internistische Onkologie. J Clin Oncol 26: 1435-1442, 2008.

7 Koizumi W, Takiuchi H, Yamada Y, Boku N, Fuse N, Muro K, Komatsu Y and Tsuburaya A: Phase II study of oxaliplatin plus S-1 as first-line treatment for advanced gastric cancer (G-SOX study). Ann Oncol 21: 1001-1005, 2010.

8 Yamada Y, Higuchi K, Nishikawa K, Gotoh M, Fuse N, Sugimoto N, Nishina T, Amagai K, Chin K, Niwa Y, Tsuji A, Imamura $H$, Tsuda $M$, Yasui $H$, Fujii $H$, Yamaguchi K, Yasui $H$, Hironaka S, Shimada K, Miwa H, Hamada C and Hyodo I: Phase III study comparing oxaliplatin plus S-1 with cisplatin plus S-1 in chemotherapy-naïve patients with advanced gastric cancer. Ann Oncol 26: 141-148, 2015.

9 Gibbons GR, Page JD, Mauldin SK, Husain I and Chaney SG: Role of carrier ligand in platinum resistance in L1210 cells. Cancer Res 50: 6497-6501, 1990.

10 Mamenta EL, Poma EE, Kaufmann WK, Delmastro DA, Grady HL and Chaney SG: Enhanced replicative bypass of platinumDNA adducts in cisplatin-resistant human ovarian carcinoma cell lines. Cancer Res 54: 3500-3505, 1994.

11 Duckett DR, Drummond JT, Murchie AI, Reardon JT, Sancar A, Lilley DM and Modrich P: Human MutSalpha recognizes damaged DNA base pairs containing $O^{6}$-methylguanine, $O^{4}$ methylthymine, or the cisplatin-d(GpG) adduct. Proc Natl Acad Sci USA 93: 6443-6447, 1996.

12 Fink D, Nebel S, Aeb Si, Zheng H, Cenni B, Nehmé A, Christen RD and Howell SB. The role of DNA mismatch repair in platinum drug resistance: Cancer Res 56: 4881-4886, 1996.

13 Brown R, Hirst GL, Gallagher WM, McIlwrath AJ, Margison GP, van der Zee AG and Anthoney DA: hMLH1 expression and cellular responses of ovarian tumour cells to treatment with cytotoxic anticancer agents. Oncogene 15: 45-52, 1997.

14 Nehmé A, Baskaran R, Nebel S, Fink D, Howell SB, Wang JY and Christen RD: Induction of JNK and c-ABL signalling by cisplatin and oxaliplatin in mismatch repair-proficient and deficient cells. Br J Cancer 79: 1104-1110, 1999.

15 Di Francesco AM, Ruggiero A and Riccardi R: Cellular and molecular aspects of drugs of the future: oxaliplatin. Cell Mol Life Sci 59: 1914-1927, 2002.

16 Kollmannsberger C, Rick O, Derigs HG, Schleucher N, Schöffski P, Beyer J, Schoch R, Sayer HG, Gerl A, Kuczyk M, Spott C, Kanz L and Bokemeyer C: Activity of oxaliplatin in patients with relapsed or cisplatin-refractory germ cell cancer: a study of the German Testicular Cancer Study Group. J Clin Oncol 20: 2031-2037, 2002.

17 Al-Batran SE, Kerber A, Atmaca A, Dechow C, Reitsamer E, Schmidt S, Kolassa Y, Neumann A, Weidmann E, Hartmann JT, Jäger E: Mitomycin C, 5-fluorouracil, leucovorin, and oxaliplatin as a salvage therapy for patients with cisplatin-resistant advanced gastric cancer: a phase I dose escalation trial. Onkologie 30: 29-34, 2007.

18 Kim DY, Kim JH, Lee SH, Kim TY, Heo DS, Bang YJ and Kim NK: Phase II study of oxaliplatin, 5-fluorouracil and leucovorin in previously platinum treated patients with advanced gastric cancer. Ann Oncol 14: 383-387, 2003. 
19 Japan Clinical Oncology Group Study (JCOG0501): Randomized phase III trial of surgery plus neoadjuvant TS-1 and cisplatin compared with surgery alone for type 4 and large type 3 gastric cancer. [Online]. Available: https://upload.umin.ac.jp/ cgi-open-bin/ctr/ctr.cgi?function=brows \& action=brows \& recptno $=$ R000000356\&type $=$ summary \&language $=J$.

20 Satoh $\mathrm{T}$ and Sakata Yuh: A phase II study of systemic chemotherapy with docetaxel, CDDP, and S-1 followed by surgery in advanced gastric cancer with extensive lymph node metastasis (JCOG1002). Expert Opin Pharmacother 13: 1943-1959, 2012.

21 Eisenhauer EA, Therasse P, Bogaerts J, Schwartz LH, Sargent D, Ford R, Dancey J, Arbuck S, Gwyther S, Mooney M, Rubinstein L, Shankar L, Dodd L, Kaplan R, Lacombe D and Verweij J: New Response Evaluation Criteria in Solid Tumours: revised RECIST guideline (version 1.1). Eur J Cancer 45: 228-247, 2009.

22 Cancer Therapy Evaluation Program, National Cancer Institute. Common Terminology Criteria for Adverse Events (CTCAE) v4.0. 2010.

23 Wilke H, Muro K, Van Cutsem E, Oh SC, Bodoky G, Shimada Y, Hironaka S, Sugimoto N, Lipatov O, Kim TY, Cunningham D, Rougier P, Komatsu Y, Ajani J, Emig M, Carlesi R, Ferry D, Chandrawansa K, Schwartz JD and Ohtsu A: Ramucirumab plus paclitaxel versus placebo plus paclitaxel in patients with previously treated advanced gastric or gastro-oesophageal junction adenocarcinoma (RAINBOW): a double-blind, randomised phase 3 trial. Lancet Oncol 15: 1224-1235, 2014.

24 Sakuramoto S, Sasako M, Yamaguchi T, Kinoshita T, Fujii M, Nashimoto A, Furukawa H, Nakajima T, Ohashi Y, Imamura H, Higashino M, Yamamura Y, Kurita A and Arai K: Adjuvant chemotherapy for gastric cancer with S-1, an oral fluoropyrimidine. N Engl J Med 357: 1810-1820, 2007.

25 Fuse N, Bando H, Chin K, Ito S, Yoshikawa T, Tsuburaya A, Terashima M, Kawashima Y, Fukunaga T, Gotoh M, Emi Y, Yoshida K, Oki E, Takahashi S, Kuriki H, Sato K and Sasako M: Adjuvant capecitabine plus oxaliplatin after D2 gastrectomy in Japanese patients with gastric cancer: a phase II study. Gastric Cancer 20: 332-340, 2017.
26 Yoshikawa T, Sasako M, Yamamoto S, Sano T, Imamura H, Fujitani K, Oshita H, Ito S, Kawashima Y and Fukushima N: Phase II study of neoadjuvant chemotherapy and extended surgery for locally advanced gastric cancer. Br J Surg 96: 1015-1022, 2009.

27 Iwasaki Y, Sasako M, Yamamoto S, Nakamura K, Sano T, Katai $\mathrm{H}$, Tsujinaka T, Nashimoto A, Fukushima $\mathrm{N}$ and Tsuburaya A: Phase II study of preoperative chemotherapy with S-1 and cisplatin followed by gastrectomy for clinically resectable type 4 and large type 3 gastric cancers (JCOG0210). J Surg Oncol 107: 741-745, 2013.

28 Yoshikawa T, Nakamura K, Tsuburaya A, Sano T, Mizusawa J, Katai H, Kurita A, Uyama I, Nomura E and Sasako M: A phase II study of preoperative chemotherapy with S-1 (S) and cisplatin (P) followed by D3 gastrectomy for gastric cancer (GC) with extensive lymph node metastasis (ELM): Survival results of JCOG0405. J Clin Oncol (Meeting Abstracts) 29(4 suppl): 70, 2011.

29 Thuss-Patience PC, Kretzschmar A, Bichev D, Deist T, Hinke A, Breithaupt K, Dogan Y, Gebauer B, Schumacher G and Reichardt P: Survival advantage for irinotecan versus best supportive care as second-line chemotherapy in gastric cancer--a randomised phase III study of the Arbeitsgemeinschaft Internistische Onkologie (AIO). Eur J Cancer 47: 2306-2314, 2011.

30 Hironaka S, Ueda S, Yasui H, Nishina T, Tsuda M, Tsumura T, Sugimoto N, Shimodaira H, Tokunaga S, Moriwaki T, Esaki T, Nagase M, Fujitani K, Yamaguchi K, Ura T, Hamamoto Y, Morita S, Okamoto I, Boku N and Hyodo I: Randomized, openlabel, phase III study comparing irinotecan with paclitaxel in patients with advanced gastric cancer without severe peritoneal metastasis after failure of prior combination chemotherapy using fluoropyrimidine plus platinum: WJOG 4007 trial. J Clin Oncol 31: 4438-4444, 2013.

Received February 27, 2017

Revised March 21, 2017

Accepted March 24, 2017 